\title{
Secondary subfertility among the couple attending selected fertility centre of Dhaka, Bangladesh
}

\author{
Sumia Bari ${ }^{1 *}$, Mosammat Shahina Begum ${ }^{2}$, Kamrun Nessa ${ }^{1}$
}

\begin{abstract}
${ }^{1}$ Department of Obstetrics and Gynecology, Enam Medical College and Hospital, Dhaka, Bangladesh
${ }^{2}$ Department of Obstetrics and Gynecology, Women's and Child Hospital, Dhaka, Bangladesh
\end{abstract}

Received: 02 January 2018

Accepted: 31 January 2018

\author{
*Correspondence: \\ Dr. Sumia Bari, \\ E-mail: bari_sumia@yahoo.com
}

Copyright: (c) the author(s), publisher and licensee Medip Academy. This is an open-access article distributed under the terms of the Creative Commons Attribution Non-Commercial License, which permits unrestricted non-commercial use, distribution, and reproduction in any medium, provided the original work is properly cited.

\begin{abstract}
Background: Couple suffering from secondary subfertility is a major health concern. Pattern involved both the male and female factors and sometimes unknown aetiology. This cross-sectional study was carried out to see the pattern of secondary subfertility among the couples attended selected fertility centres of Dhaka city to ascertain the risk factors.

Methods: A cross sectional study was carried out among the couples attended from September 2011 through March 2012. There were 190 couples were interviewed with questionnaire using the purposive sampling method and analyzed by SPSS 20.

Results: Among the 190 couples suffering from secondary subfertility, 52\% cases female factors, $13 \%$ male factors, unexplained $27 \%$ and both male and female factors lie behind $8 \%$ of cases. Among the female causes $31 \%$ were tubal factors, $26 \%$ cases PCOD, ovulatory disorders and endometriosis $21 \%$ and $22 \%$ respectively. Result revealed that the mean age of the female was 32 and $54 \%$ were obese. The women who had tubal factors had H/O MR or D\&C in significant number. Female age, weight menstrual irregularity, medical disorders and number of previous abortion were significantly correlated with secondary subfertility. Among the male factors $76 \%$ cases shows abnormal semen parameters, $12 \%$ cases coital problem, $12 \%$ cases ejaculatory problem due to chronic disease like chronic HTN, DM. Conclusions: This study concluded that proper evaluation with details personal, medical and gynaecological history of female and also male factors need to evaluate the cause and formulate a management plan to treat the secondary subfertile couple.
\end{abstract}

Keywords: BMI, PCOD, Subfertility, Tubal factors

\section{INTRODUCTION}

In clinical medicine, secondary infertility is usually defined as the inability to conceive despite exposure to pregnancy for one year (2 years in some epidemiological studies), after having conceived at least once before. ${ }^{1}$ This implies that women with secondary infertility do not necessarily have a living child.

Epidemiological data indicate that conception occurs in $84 \%$ of women within 12 months and $92 \%$ by second year of ceasing contraception. ${ }^{2}$ So infertility can be defined as inability to conceive after one or two years of regular unprotected sexual intercourse. It can be broadly divided into primary infertility where couples have never conceived previously and secondary infertility where couples have had a pregnancy, although not necessary a successful one. ${ }^{2}$ Even though the exact prevalence of infertility in Bangladesh is difficult to ascertain, it affects 10 to $15 \%$ couples in the western world. ${ }^{3}$ There has not been any major increase in the prevalence of infertility in recent years, but there is a greater awareness of the problem and also availability of more effective treatments like in vitro fertilization even in countries like Bangladesh. Either the male and female partners can be 
responsible for infertility in around $30 \%$ cases or both are involved in another 25 to $30 \%$ cases. In the remaining 10 to $15 \%$ case, no cause could be found out, which is known as unexplained infertility. ${ }^{4}$

Studies looking at prevalence of infertility have all used slightly different definitions making comparison and overall estimates of secondary infertility difficult. Nevertheless, it is well established that primary infertility is much more common than secondary infertility in resource-rich countries but that the reverse is true in resource-poor countries.5 According to Bangladesh Fertility Society, the causes of such a situation of infertility were menstrual regulation, delayed marriage and environmental pollution.

Infertility affects a relatively large number of couples at some point in their reproductive lives - globally, between 50 and 80 million couples (WHO, 1994). Moreover, in pronatalist cultures such as those of India, and South Asia more generally, the consequences of infertility for women can be devastating. One estimate of overall primary and secondary infertility in South Asia drawn on the basis of women at the end of their reproductive careers (aged 4549) suggests a rate in the range of 10 percent, 8 percent in India, 10 percent in Pakistan, 11 percent in Sri Lanka, 12 percent in Nepal and 15 percent in Bangladesh. ${ }^{6}$

Though the International Conference on Population and Development (ICPD) programme of action states that reproductive health services should include the prevention and appropriate treatment of infertility (United Nations, 1994), there is inadequate focus on infertility in South Asian reproductive health programme. ${ }^{7}$ Traditionally, childless women in Bangladesh experience stigma and isolation. Infertility can threaten a woman's identity, status and economic security and consequently, be a major source of anxiety leading to lowered selfesteem and a sense of powerlessness. Stigmatizing beliefs, limited male participation, cost, indifferent quality of care, and lack of services in the public sector are major barriers to prompt and appropriate treatment seeking.

The purpose of this study was generating information regarding the pattern of secondary subfetility, clinical profile and gynaecological features of the female subject, contributing male factors. It ascertains the sociodemographic and socio-economic background of the respondents to see their association with the level of subfertility and can help in decision making in this sector through early diagnosis and prevention of secondary subfertility cases to reduce social stigma.

\section{METHODS}

A cross-sectional type of study was conducted in a selected fertility centres in Dhaka city of Bangladesh. The duration of the study was from September 2011 through March 2012 among the couples suffering from secondary subfertility attending this centre. We include the couple who are suffering from secondary sub fertility for more than two years, had no living issues and can showed all the documentary reports of their investigation and treatment. The female partner aged above 38 years excluded from the study.

Data was collected by using face to face interview with the couple suffering from secondary subfertility in the study area through a semi structured questionnaire. An informed consent was ensured. Some secondary data was collected from treatment file with the patient. Instrument for data collection were semi-structured questionnaire, observational checklist (including questionnaire, weight and height measurement instrument and available investigation reports). Socio demographic and other previous documented pregnancy either termination (MR, abortion) or not (live birth), D\&C, laparatomy, laparoscopy or hysterosalpingography reports, or any surgical interference like appendicectomy, myomectomy, cystectomy recorded. Hormonal reports of female partner and semen analysis of male partner were collected. Treatment of infertility like ovulation induction by $\mathrm{CC} /$ Letroz or GnRH or any previous procedure like IUI, IVF were noted. The data from the complete questionnaires was entered in SPSS 20 and analyzed.

\section{RESULTS}

In this study 190 couples suffering from secondary subfertility were included. The mean age of the female partner was $32 \pm 2.7$ years and that of male partner was $39 \pm 4.2$ years. Minimum age of the female was 23 and that of male 27. Maximum age of the female was 38 and that of male 53 .

Table 1: Distribution of female respondents by age.

\begin{tabular}{|lll|}
\hline Age of female respondents & Frequency & Percent \\
\hline 23 & 27 & 14 \\
\hline 24 & 11 & 6 \\
\hline 26 & 5 & 3 \\
\hline 29 & 7 & 4 \\
\hline 32 & 27 & 14 \\
\hline 33 & 7 & 4 \\
\hline 34 & 38 & 20 \\
\hline 35 & 14 & 7 \\
\hline 36 & 15 & 8 \\
\hline 37 & 24 & 13 \\
\hline 38 & 15 & 8 \\
\hline
\end{tabular}

Table 1 shows that the mean age of the female respondents was 32 , median age 34 . The minimum age group of female respondents were 23 and maximum age group of females were 38 .

According to the religion $85 \%$ respondents were Muslim, $12 \%$ Hindu and 3\% Christian. Most of the women were housewife $(61 \%)$ and rest were service holder (39\%). 
Table 2: Distribution of respondents by religion.

\begin{tabular}{|lll|}
\hline Religion & Frequency & Percent \\
\hline Muslim & 161 & 85 \\
\hline Hindu & 22 & 12 \\
\hline Christian & 7 & 3 \\
\hline Total & 190 & 100 \\
\hline
\end{tabular}

In the present study, though we did not find any significant association ( $\mathrm{P}$ value $<0.05$ ) of male occupation with cause of infertility among the number of male respondent, however, it should be well adjusted according to the type of respondents. Table 3 shows that $61 \%$ of female respondents were housewife, $39 \%$ were servicing.

\section{Table 3: Distribution of female respondents by} occupation.

\begin{tabular}{|lll|}
\hline Occupation of the wife & Frequency & Percent \\
\hline Housewife & 116 & 61 \\
\hline Service holder & 74 & 39 \\
\hline Total & 190 & 100 \\
\hline
\end{tabular}

In the study respondents $13 \%$ of women had a master's degree, $31 \%$ had a bachelor, 32\% complete their HSC, $16 \%$ SSC, $6 \%$ primary level and only $2 \%$ had no institutional knowledge. The level of education among the male respondents was $16 \%$ complete their masters, $41 \%$ bachelor, $35 \%$ HSC, $7 \%$ SSC and only $1 \%$ had no education. And the present study shows that increasing level of education both men and women increase rate of secondary infertility which was statistically significant $(\mathrm{P}$ value <.05).

Table 4: Distribution of female respondents by education status.

\begin{tabular}{|lll|}
\hline $\begin{array}{l}\text { Education of female } \\
\text { respondents }\end{array}$ & Frequency & Percent \\
\hline No education & 4 & 2 \\
\hline Primary education & 12 & 6 \\
\hline Secondary education & 31 & 16 \\
\hline HSC & 60 & 32 \\
\hline Bachelor's degree & 59 & 31 \\
\hline Masters & 24 & 13 \\
\hline Total & 190 & 100 \\
\hline
\end{tabular}

Table 4 shows that $2 \%$ of female respondents were no Institutional education, $6 \%$ primary level,16\% secondary level,32\% complete HSC level,31\%complete their Bachelordegree, $13 \%$ complete their Masters.

Regarding economic status couple who were attending in the fertility centre, $4 \%$ earned less than 10 thousand Taka per month though they have some land and came this centre after a long time suffering from secondary subfertility. $7 \%$ couple earned in between 10 to 20 thousand, $11 \%$ earned 20 to 30 thousand, $15 \% 30$ to 40 thousand, $47 \% 40$ to 50 thousand and 17\% above 60 thousand per month. As the treatment of infertility is costly at tertiary level, so majority couple come from higher income group.

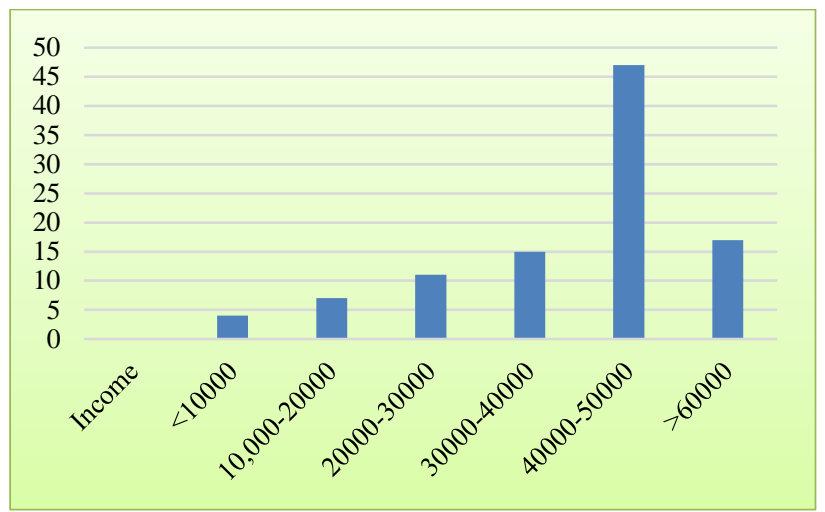

Figure 1: distribution of respondents by monthly income.

In present study among the 190 couples suffering from secondary subfertility, the percentage of female factors was $52 \%$, male factors were $13 \%$, unexplained $27 \%$ and in $8 \%$ both male and female factors lie behind.

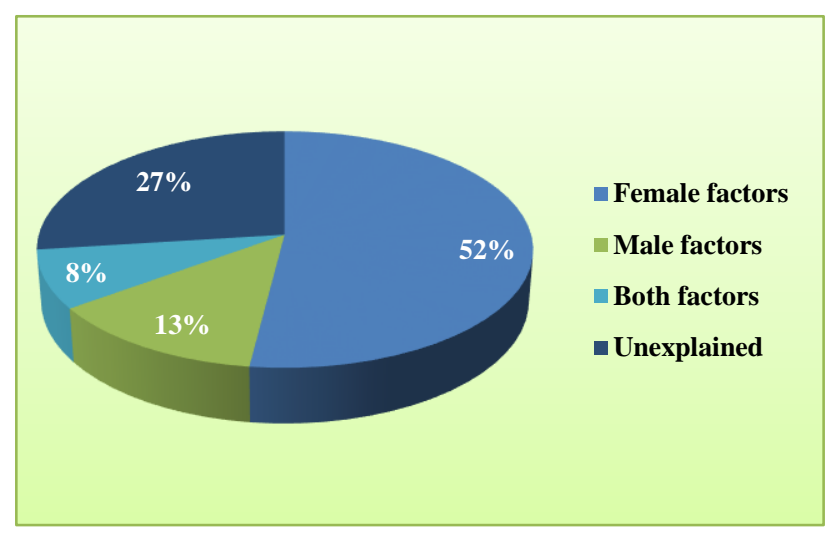

Figure 2: Causes of subfertility among the study couples.

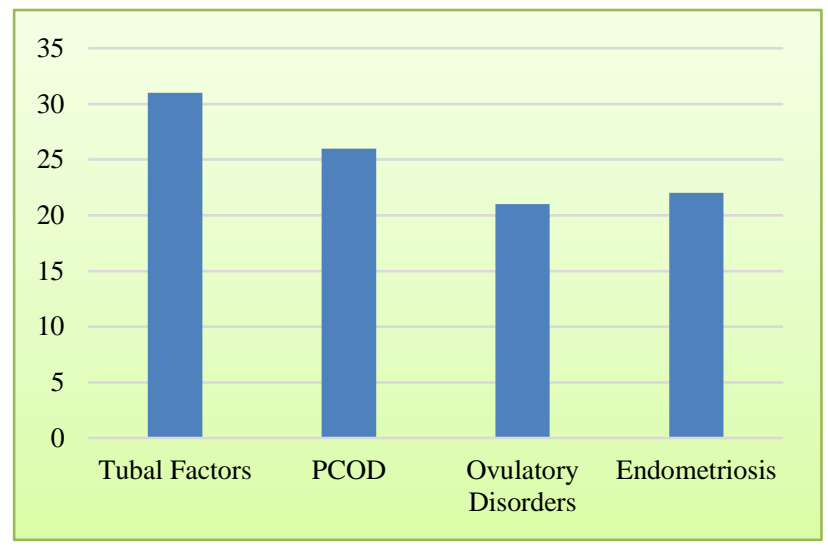

Figure 3: Distribution of cause of secondary subfertility among the female respondent 
Table 5: Distribution of female respondents by BMI.

\begin{tabular}{|lll|}
\hline BMI & Frequency & Percent \\
\hline$<18$ (underweight) & 14 & 7 \\
\hline $19-24$ (normal) & 41 & 22 \\
\hline $25-29$ (overweight) & 33 & 17 \\
\hline$>30$ (obese) & 102 & 54 \\
\hline Total & 190 & 100 \\
\hline
\end{tabular}

In the present study (women) $7 \%$ were underweight, $22 \%$ were normal $17 \%$ were overweight, $54 \%$ respondents were obese.

Table 5 Shows $7 \%$ were underweight, $22 \%$ were normal $17 \%$ was overweight, and $54 \%$ respondents were obese. The Bar chart showing the factors of infertility among the female respondents were $31 \%$ cases tubal, $26 \%$ PCOD, $21 \%$ were ovulatory and $22 \%$ cases had endometriosis (Figure 3).

Table 6: Distribution of the female respondent who underwent MR or D\&C procedures.

\begin{tabular}{|llll|}
\hline $\begin{array}{l}\text { Female respondent underwent } \\
\text { MRR/D\&C }\end{array}$ & $\begin{array}{l}\text { History of MR } \\
\text { (frequency) }\end{array}$ & $\begin{array}{l}\text { History of D\&C } \\
\text { (frequency) }\end{array}$ & $\begin{array}{l}\text { Total no. of women underwent } \\
\text { MR or D\&C (frequency/percent) }\end{array}$ \\
\hline Tubal factors $\mathrm{N}=60(31 \%)$ & 27 & 25 & $52(86.7 \%)$ \\
\hline PCOD N $=48(26 \%)$ & 08 & 12 & $20(40.8 \%)$ \\
\hline Ovulatory disorders $\mathrm{N}=40(21 \%)$ & 13 & 09 & $22(55 \%)$ \\
\hline Endometriosis $\mathrm{N}=42(22 \%)$ & 05 & 03 & $08(19 \%)$ \\
\hline Total $(190)$ & 53 & 49 & $102(53.68 \%)$ \\
\hline
\end{tabular}

Table 6 showing $86.7 \%$ women who had tubal cause, $40.8 \%$ who had PCOD, 55\% women of ovulatory disorders and $19 \%$ women with endometriosis underwent MR or D\&C procedure.

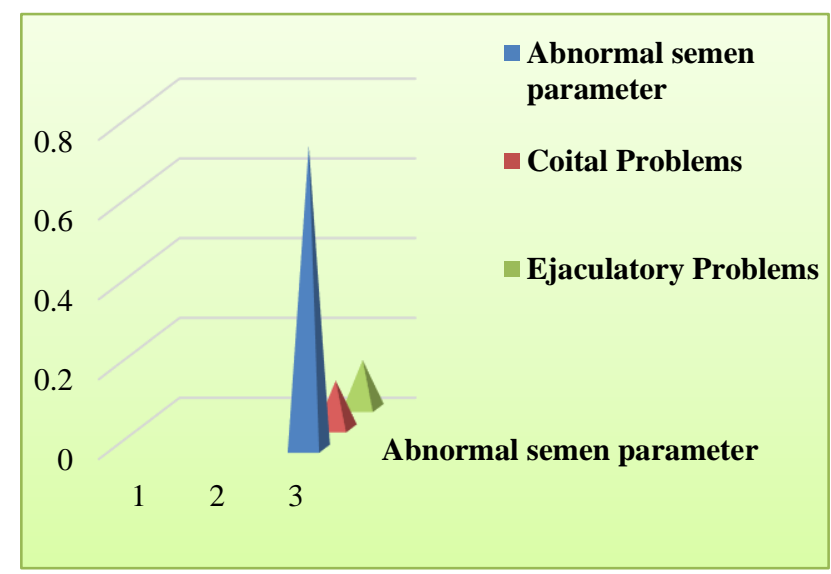

Figure 4: Distribution of male factors contributing as a cause of secondary subfertility among the male respondents.

Figure 4 shows the male contributing factors in secondary subfertility. $76 \%$ cases show abnormal semen parameters, $12 \%$ cases coital problems and $12 \%$ cases ejaculatory problems.

\section{DISCUSSION}

Infertility is a fairly common problem in our country and has got more social and clinical significance is a basically in developing country like Bangladesh. A cross sectional study was done in a selected fertility centre, which is one of the busiest centres at the tertiary level in Dhaka city in Bangladesh.

This study shows that mean age of the female partner was 32 and that of male partner was 39. Maximum age of the female was 38 and that of male 53. Different research shows that a strong association exist between subfertility and increasing female age. The reduction in fertility is greatest in women in their late 30 s and early 40s. For women aged 35-39 years the chance of conceiving spontaneously is half of the women aged 19-26. The natural cumulative conception rate in the 35-39 age group is around $60 \%$ at one year and $85 \%$ at two years. Increasing rates of primary and secondary infertility seen with increasing ages of the couple is well documented.

The findings of the present study are compatible with references in medical literature that female fertility begins to decline around 30 years of age and a fall in the male fertility potential around 40 years of age. ${ }^{8,9}$ Caminiti identifies age as the most significant factor contributing towards infertility. ${ }^{10}$ Koetswang et al reported a similar increase in secondary infertility with advancing age among the women of the reproductive age' group. Increasing age at marriage in both males and females has been shown to play a role in fertility decline. This may partly be attributed to the fact. In our study age of the male respondents was minimum 27 and maximum 53 and a mean age was 39 . Recent evidence shows that male fertility also declines with age.

According to the religion $85 \%$ respondents were Muslims, $12 \%$ Hindu and 3\% Christian. There was no such evidence that secondary subfertility has any specific relation with religion as it is totally depending upon 
personal behaviour. However, some religious perception, customs may help to developed personal hygiene, safety sex practice thus prevent infection of genital tracts and tubal pathology.

Occupation is an important factor in case of infertility especially in the male. Though different occupation affects male and female, in our study most of the female were housewife $(61 \%)$ and rest $(39 \%)$ were servicing and no association was found in the study.

In case of male respondents, the type of job of male partner related with STI, which is a main cause of tubal block in terms of male and female both. As the job environment (hot or cold) which affect semen quality, stressful job related to decrease gonadotropin secretion, thus decrease sperm count or related to some chronic disease like HTN or DM which also affect male spermatogenesis directly or indirectly due to taking medicine to control them. There are also some coital problems like premature ejaculation, retrograde ejaculation which also play role in infertility. Some other factors like STD also a cause of oligospermia or azospermia due to obstructive pathology in male genital tract.

In the present study, though we did not find any significant association ( $P$ value $<0.05$ ) of male occupation with cause of infertility among the number of male respondent, however, it should be well adjusted according to the type of respondents.

Education level of both partner plays an important role in the health status at any level. However, maintaining personal hygiene, safe sex practice, timed intercourse at the time of ovulation, prevention and treatment of STD, all of which include proper knowledge and attitude of the couple. Moreover, treatment seeking behaviour also seen high among the educated couples.

In our study, $13 \%$ of women had a Master's degree, $31 \%$ had a Bachelor, $32 \%$ complete their HSC, $16 \%$ SSC, $6 \%$ Primary level and only $2 \%$ had no institutional knowledge. Educations of the female partner have a great role in the cause, diagnosis, treatment and prevention of secondary subfertility. ${ }^{12}$

Knowledge about the reproductive health is necessary in every aspect. The level of education among the male respondents was $16 \%$ complete their Masters, $41 \%$ Bachelor, 35\% HSC, 7\% SSC and only 1\% had no education. And the present study shows that increasing level of education both men and women increase rate of secondary infertility which was statistically significant $(\mathrm{P}$ value <.05). This effect probably due to larger number of couple who are living in the city and can afford the cost attend in the centre than the rural couple who have low level of education. This effect is also probably age related due to postponement of marriage by those who remain in the education process for a longer time. ${ }^{13}$
Regarding economic status couple who were attending in the fertility centre, $10 \%$ earned less than 10 thousand Taka per month though they have some land and came this centre after a long time suffering from secondary subfertility. $7 \%$ couple earned in between 10 to 20 thousand, $11 \%$ earned 20 to 30 thousand, $15 \% 30$ to 40 thousand, $47 \% 40$ to 50 thousand and $17 \%$ above 60 thousand per month. As the treatment of infertility is costly at tertiary level, so majority couple come from higher income group.

In present study among the 190 couples suffering from secondary subfertility, the percentage of female factors was $52 \%$, male factors were $13 \%$, unexplained $27 \%$ and in $8 \%$ both male and female factors lie behind.

Major group of women which shows 31 percent was due to tubal block and majority of women had tubal cause were history of MR or D\&C. Though they were mostly institutional and even by trained person, but study signifies that infection prevention is not optimum as a result tubal damage occurred through subclinical infection. There were 2 cases had a history of TB in the past, which indicate there may be genital TB which causes tubal damage and block. Female respondents having tubal cause had history of laparotomy 2 cases, 1 had myomectomy and 3 had caesarean section.

Though it is assumed that the main cause of secondary subfertility is the tubal pathology. However, in this study big percentage (26) of female was suffering from Poly Cystic Ovarian Disease (PCOD) in which they have a good association with BMI (overweight or obese), irregular menstruation, hormonal imbalance, DM, history of abortion and past medical history of cystic ovaries. Which indicate the trend of PCOD is gradually increase among the women reproductive age group.

There is a strong familial or genetic association in patient with PCOD. Third group of women had ovulatory disturbance (10 percent) was irregular ovulation or anovulation named as non PCO ovulatory disorder. There was hormonal imbalance; history of ovarian cyst, endometriosis and DM was found in some cases of ovulatory disorder. Women suffering from endometriosis $(10 \%)$ had a history of overian cyst and dysmenorrhoea, dyspareunia and history of abortion. In case of endometriosis multiple factors work against fertility. Dyspareunia may not help the couple to timed intercourse, difficulties in ascend of sperm, chocolate cyst interferes with ovulation, and pelvic adhesion prevents ovum pickup and fertilization.

Women suffering from secondary subfertility present with hormonal imbalance like Hypothyroidism or Hyperprolactinaemia. In our study 45 cases were Hypothyroid present with obesity and history of abortion and associated with Hyperprolactinaemia. Thyroid hormone plays a major role in reproductive health of a 
female as correction of hypothyroid state simultaneously correct hyperprolactinaemia.

In the present study 15 cases had uterine myoma and 3 cases had $\mathrm{H} / \mathrm{O}$ myomectomy who had repeated history of abortion. However, before going for myomectomy, husband semen analysis must be ensured. Unfortunately, in the study 5 cases were found as Premature Overian Failure (POF).

Anti-Mullerian Hormone (AMH) is an excellent diagnostic aid to evaluate the female fertility potential as the level in the blood indicates its optimum or borderline potentiality which helps the couple to make an early decision. ${ }^{14}$ In this study the female above 35 years had the investigation show that 42 percent had low fertility potential, 34 percent intermediate and 24 percent optimum fertility potential.

Among the male respondents, $13 \%$ show abnormal semen parameter in the form of oligospermia and asthenospermia. Though there is an association between occupation and working environment, however in the study there was no association was found.

Moreover, significant association was found among the man with increased level of education. But there was a significant association between past medical history of HTN, DM, CKD and lung disease with male partner had coital problem, abnormal semen parameter. Though the past surgical history had no significant association ( $\mathrm{P}$ value $>.05$ ), but 3 male having coital problem had history of 1 hernia repair, 1 vasectomy, 1 Appendicectomy operation.

In case of seconday subfertility patient trying for pregnancy average time period 5 years. Though they were young (age <30 years) it was accepted but though who were elder age group (age $>35$ ) it was late. As the ovarian reserve was also decrease by this time their hormonal evaluation report like FSH, Estradiol, AMH become the range of decrease fertility potential. ${ }^{15}$

The women who had history of previous D\&C, MR or delivery present with chronic lower abdominal pain, dysmenorrhoea, dyspareunia, treatment seeking for more than 5 years. Three of them diagnosed as a case of Asherman's syndrome. Two patients had a history of TB, present with underweight, irregular menstruation, chronic lower abdominal pain.

Female with Poly Cystic Ovary Disease (PCOD) most of them were overweight and obese having hirsutism, amenorrhoea, irregular menstruation, weight gain had an abnormal ratio of serum $\mathrm{LH}$ and $\mathrm{FSH}$, hypeprolactinaemia, DM. Five female respondents present with amenorrhoea or irregular menstruation with history of hot flush showinh high level of serum FSH with atrophied overies on TVS diagnosed as Premature Overian Failure (POF).
Female respondent's age above 35 years show decrease fertility potential or no fertility potential with the report of Anti-Mullerian Hormone (AMH). Which is important to stop the couple to take unnecessary hormone to induce or stimulate ovaries.

\section{CONCLUSION}

This study concluded that proper evaluation with details personal, medical and gynaecological history of female and also male factors need to evaluate the cause and formulate a management plan to treat the secondary sub fertile couple.

\section{Funding: No funding sources \\ Conflict of interest: None declared \\ Ethical approval: The study was approved by the Institutional Ethics Committee}

\section{REFERENCES}

1. WHO. Challenges in reproductive health research: biennial report 1992-1993. Geneva: World Health Organization. World Health Organization. 1994:186.

2. Qureshi MS, Khan T. Infertility in Pakistan; population research 1980-1990. Karachi: National Res Institute of Fertility Control; 1980-1990:222-31.

3. Hakim A, Sultan M, Uddin F. Pakistan reproductive health and family planning survey 2000-01: preliminary report. Islamabad: National Institute of Population Studies; 2001:30.

4. Najmi SR. Maternal mortality and morbidity: a hospital-based study. J Coll Physicians Surg Pak. 1995;5:67-70.

5. Singh $S$, Wulf $D$. The likelihood of induced abortion among women hospitalized for abortion complications in four Latin American countries. Int Fam Plann Persp. 1993;19:134-41.

6. Rehman N. Unsafe abortion: magnitude and perceptions. J Fam Plann Assoc Pak. 1998;27:22-3.

7. WHO. Infertility: a tabulation of available data on prevalence of primary and secondary infertility. Geneva: programme on maternal and child health and family planning, division of family health. World Health Organization; 1991:3.

8. Adetoro OO, Ebomoyi EW. The prevalence of infertility in a rural Nigerian community. Afr J Med Med Sci. 1991;20:23-7.

9. Shireen JJ. Infertility in India: levels, patterns and consequences: priorities for social research. J Fam Welf. 1998;44:15-24.

10. Czerwinski BS. Adult feminine hygiene practices. Appl Nurs Res. 1996;9:123-9.

11. Narayan KA, Pelto SPJ, Veerammal S. Puberty rituals, reproductive knowledge and health of adolescent school girls in South India. Asia-Pacific Popul J. 2001;16:225-38.

12. Czerwinski BS, Wardell DW, Yoder LH, Connelly LM, Ternus M, Pitts K, et al. Variations in feminine hygiene practices of military female in deployed and 
noncombatant environments. Mil Med. 2001;166:152-8.

13. Mathews A. Menstruation issues in Bangladesh. Footsteps. 1995;24:2-3.

14. Bresnick ER. A holistic approach to the treatment of the crisis of infertility. J Marital Fam Therap. $1981 ; 7: 181-8$
15. Holditch-Davis D, Sandelowski M, Harris BG. Infertility and early parent-infant interactions. J Advanced Nurs. 1998;27:992.

Cite this article as: Bari S, Begum MS, Nessa K. Secondary subfertility among the couple attending selected fertility centre of Dhaka, Bangladesh. Int J Reprod Contracept Obstet Gynecol 2018;7:817-23. 